\title{
Applicability of T-S algorithms to the Canary Islands region*
}

\author{
A. MARRERO-DÍAZ, J. L. PELEGRÍ, A. RODRÍGUEZ-SANTANA and P. SANGRÀ \\ Departamento de Física, Facultad de Ciencias del Mar, Campus Universitario de Tafira, 35017. Las Palmas de \\ Gran Canaria, Canary Islands, Spain. E-mail: angeles.marrero@fisica.ulpgc.es
}

\begin{abstract}
SUMMARY: The high cost of oceanographic cruises often makes it advisable to use opportunity vessels for simple measurements, such as determining the temperature of the water column with expandable bathythermographs (XBT). In this work we examine the goodness and reliability of a method aimed at obtaining the maximum possible information from XBT data, and we apply it to the Canary Islands region. It consists in calculating analytic relations between temperature and salinity from historical conductivity-temperature-depth (CTD) data for the region, which are then used to hindcast/forecast the salinity and density distribution, as well as the distribution of other inferred quantities such as velocity. A hindcasting is carried out using direct independent temperature measurements obtained from a hydrographic cruise south of the island of Gran Canaria. At depths greater than 100-150 m the results show good agreement with the calculations obtained from CTD in situ data.
\end{abstract}

Key words: T-S relationship, Canary Islands Region, geostrophic transport, XBT probe, hydrography.

\section{INTRODUCTION}

When designing a hydrographic cruise we must take into account different logistic aspects, such as the cost of ship operation and the necessity of fast measurements in regions where the oceanographic structures change rapidly in time. These fast measurements at a relatively low cost can usually be done from opportunity vessels. The sort of instrumentation used from this type of ship, however, is usually very limited because it cannot be expensive and its operation must be either automatic or fairly simple.

The development of strategies for taking and properly using measurements obtained from oppor-

\footnotetext{
*Received May 29, 2000. Accepted November 14, 2000.
}

tunity vessels is certainly an issue of great relevance for the future of oceanography. The development of new techniques and instruments must come together with the advance of methodologies for checking the reliability and usefulness of these measurements. One example is the use of expandable bathythermographs (XBTs), which are routinely launched from moving ships along a number of transoceanic lines. XBTs may also be launched from smaller and relatively inexpensive ships to complement hydrographic cruises, either to provide a preliminary gross overview of the temperature field in the region of interest or to follow the evolution of specific mesoscalar features. XBTs, however, only provide the temperature field, and are in themselves insufficient to calculate other important variables such as the density, geopotential anomaly, or geostrophic 
transport. The calculation of these quantities is possible but requires the establishment of a precise methodology, including the assessment of the quality of the inferred values.

Several authors have previously used mean temperature-salinity (T-S) curves to obtain the dynamic height or the geopotential anomaly from XBT data (Stommel, 1947; Emery, 1975; Emery and Wert, 1976; Flierl, 1978; Siedler and Stramma, 1983; Army and Bray, 1982; Emery et al., 1986). In most of these works a rather simple method was employed, what we may call the standard T-S method, which basically consisted of the following four steps. First, historical CTD data is used to derive a mean T-S curve for spatial boxes that range between $2 \times 2^{\circ}$ and $10 \times 10^{\circ}$. Second, the data is grouped by temperature intervals. Third, a salinity value is assigned to each temperature interval. Finally, a moving-average filter is applied to the data in order to obtain a smoothed salinity curve that maintains the water mass characteristics. In some of these works some error analysis was performed, essentially aimed at comparing the derived values with real values, which led to the conclusion that the method is appropriate for estimating geopotential anomalies from XBT data.

Emery (1975) and Emery and Wert (1976) first applied the above method to calculate the dynamic height in a number of boxes within the Pacific Ocean. In particular, Emery (1975) examined the influence of the box size on the results and appreciated the difficulties arising in the upper mixed layer due to the high dispersion in T-S values. Siedler and Stramma (1983) examined the applicability of this method for computing the geopotential anomalies in the Northeast Atlantic Ocean. These authors also tested alternative methods, like the use of T-S relationships at selected pressure levels (Flierl, 1978) and the use of density-pressure $(\sigma-\mathrm{T})$ relationships when the T-S diagrams showed a very high dispersion. Siedler and Stramma (1983) concluded that the standard T-S diagram method was appropriate for calculating the geopotential anomaly from temperature data within the Canary basin.

So far, however, little effort has been addressed at producing a systematic approach to the problem, to prevent a graphic inference of salinity and error bars in the derived quantities. Marrero-Díaz et al. (1997) avoided the subjectivity in the assignment of a salinity value to a temperature interval by working out polynomial relations between salinity and temperature. Such a polynomial not only provides an easy and objective way to infer salinity from temperature, but also gives error estimates. More recently, Rodríguez-Santana et al. (1999) estimated the errors associated with inferred quantities such as density, dynamic height and geostrophic velocity, both using a propagation error and the Montecarlo Method. In this work we further examine MarreroDíaz et al.'s (1997) method in order to asses its applicability for calculating density as well as other derived quantities such as dynamic height and geostrophic velocity, and to provide estimates for the relative errors involved in the calculations. The method is applied to $2 \times 2^{\circ}$ boxes south of Gran Canaria island, a region where mesoscalar structures are commonly observed (Barton, 1987; Arístegui et al., 1994; Arístegui et al., 1997; Hernández-Guerra, 1990; Hernández-Guerra et al., 1993; Sangrà, 1995; Tejera, 1996).

\section{T-S ALGORITHMS FOR THE EASTERN ATLANTIC OCEAN}

Most previous works that looked for T-S mean curves in rectangular regions of the Atlantic Ocean used cubic splines and eliminated erroneous data with moving-average filters (Emery, 1975; Emery and Wert, 1976; Siedler and Stramma, 1983; Emery et al., 1986). Some of these works (Siedler and Stramma, 1983) also proved that it was possible to calculate geopotential anomalies from temperature data. These efforts, however, did not produce analytic relationships that were easy to implement in computer programs and capable of providing salinity and density from temperature data. These circumstances, together with a relatively large field programme launching XBTs from opportunity vessels, led us to examine historical data looking for such analytic relationships in relatively small rectangular boxes $\left(2^{\circ} \times 2^{\circ}\right)$.

To obtain the mean T-S analytic relationships we searched for CTD data covering the whole study area, which included different seasons and years. These data were obtained from the databases of the French IFREMER and the American NODC, as well as from several cruises in the region: Ignat Pavlyuchenkov (Velez-Muñoz, 1992), Hespérides 9308 (Navarro-Pérez et al., 1994), and P202 (Institut für Meereskunde). These data sets covered the region off Northwest Africa, from the African coast to $19^{\circ} \mathrm{W}$ and between 26 and $38^{\circ} \mathrm{N}$. The total number of stations analysed was 779 and the total num- 
ber of salinity-temperature pairs of data was 73,506. Such a large amount of data allowed a resolution of $2^{\circ} \times 2^{\circ}$, higher than ever attained for this region. Since the cruises were not evenly distributed in time, we could not examine a possible seasonal variation in the T-S algorithms. It is expected, however, that this variation will be considerably small below the top 100 or $150 \mathrm{~m}$, where the seasonal surface mixed layer is formed (Tomczak and Godfrey, 1994; Ratsimandresy et al., 2001).

The very diverse nature of the data, some of it from as early as 1936, forced us to perform a careful quality control. We observed that most data prior to 1970 showed a T-S behaviour that diverged considerably from the best-fit curve, so we decided to systematically eliminate such data. Additionally, all stations near the African coastline of less than $100 \mathrm{~m}$ depth were not considered because of the very large seasonal influence on these shallow waters (Siedler and Stramma, 1983).

The typical T-S curves for the study region show the presence of North Atlantic and South Atlantic Central Waters (NACW and SACW). They also show an elbow-type portion corresponding to Antarctic Intermediate Water (AAIW), located at a depth that changes from one place to another within the study area, but is usually below 750 meters. When looking for an analytic T-S relationship we found that the best fit was obtained with polynomials, although the presence of AAIW was hard to simulate and caused much worse fitting at shallower depths. For this reason, and since our objective was to obtain salinity data from XBT probes that went down only to $760 \mathrm{~m}$, we decided to restrict the analytic relationships to this depth. In this manner we searched for and obtained analytic relationships for the top $760 \mathrm{~m}$ of $2^{\circ} \times 2^{\circ}$ boxes in the geographical region indicated above. The analysis of variance allowed us to obtain statistical parameters for each polynomial. The degree of the best-fit polynomials

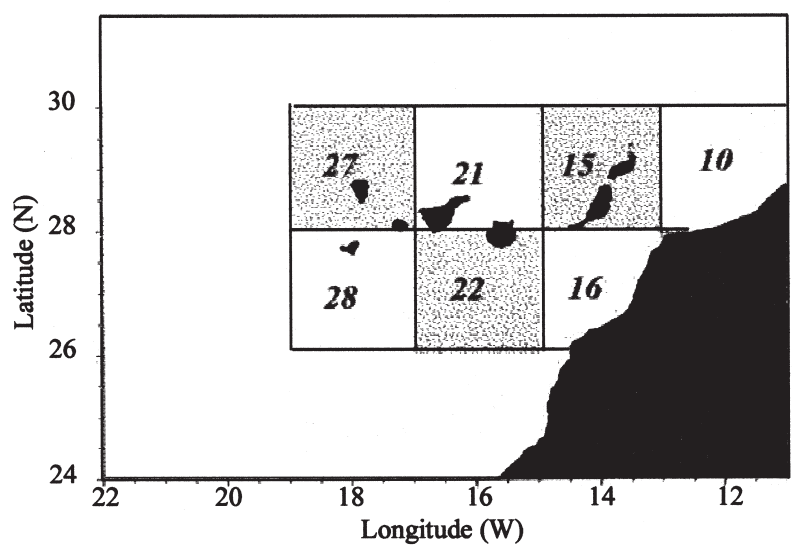

FIG. 1. - Partition of the Canary Archipielago region in $2 \times 2^{\circ}$ boxes.

was chosen using the $\mathrm{F}$ test, which ranged from $4^{\text {th }}$ to $6^{\text {th }}$ degree, the $5^{\text {th }}$ degree polynomial being the best for most cases.

Within the Canary Archipelago region, limited between the African coastline and $19^{\circ} \mathrm{W}$ and between 26 and $30^{\circ} \mathrm{N}$, we chose 7 zones for the calculation of the T-S relationships. These are identified as follows: Zone $10\left(28-30^{\circ} \mathrm{N}, 11-13^{\circ} \mathrm{W}\right)$, Zone $15\left(28-30^{\circ} \mathrm{N}, 13-15^{\circ} \mathrm{W}\right)$, Zone $16\left(26-28^{\circ} \mathrm{N}, 13-\right.$ $\left.15^{\circ} \mathrm{W}\right)$, Zone $21\left(28-30^{\circ} \mathrm{N}, 15-17^{\circ} \mathrm{W}\right)$, Zone $22(26-$ $\left.28^{\circ} \mathrm{N}, 15-17^{\circ} \mathrm{W}\right)$, Zone $27\left(28-30^{\circ} \mathrm{N}, 17-19^{\circ} \mathrm{W}\right)$, and Zone $28\left(26-28^{\circ} \mathrm{N}, 17-19^{\circ} \mathrm{W}\right)$ (see Fig. 1). Table 1 presents the coefficients of the best-fit polynomials for each of these zones, together with the standard deviation, the correlation coefficient, and the number of data points used in their calculation. We may appreciate that within the Canary Archipelago the best-fit polynomial was always of $5^{\text {th }}$ degree and the standard deviation of the salinity was never above 0.042 psu.

An example of the T-S relationship is shown in Figure 2, it corresponds to zone 22 and was done using a total of 47,285 temperature-salinity pairs of historical data from 1970, 1971, 1972, 1991, 1993 and 1994 . The grey line shows the $5^{\text {th }}$ degree poly-

TABLE 1. - Coefficients for polynomials of the type $\mathrm{S}(\mathrm{T})=\mathrm{A}+\mathrm{B}_{1} \cdot \mathrm{T}+\mathrm{B}_{2} \cdot \mathrm{T}^{2}+\mathrm{B}_{3} \cdot \mathrm{T}^{3}+\mathrm{B}_{4} \cdot \mathrm{T}^{4}+\mathrm{B}_{5} \cdot \mathrm{T}^{5}$ for each of the $2^{\circ} \times 2^{\circ}$ zones in the Canary Archipelago region. The number of data pairs used to obtain the polynomials, together with the correlation coefficient and standard deviation, are shown.

\begin{tabular}{|c|c|c|c|c|c|c|c|c|c|}
\hline \multirow{2}{*}{ zone } & \multicolumn{6}{|c|}{ Parameters } & \multirow[t]{2}{*}{ R Square } & \multirow[t]{2}{*}{$\mathrm{SD}$} & \multirow[t]{2}{*}{ data $n$. } \\
\hline & $\mathrm{A}$ & B1 & B2 & B3 & B4 & B5 & & & \\
\hline 10 & -19.803 & 20.211 & -2.9173 & 0.206327 & -0.0070962 & 0.000094928 & 0.9925 & 0.0339 & 2241 \\
\hline 15 & -7.207 & 15.672 & -2.2677 & 0.160281 & -0.0054844 & 0.000072712 & 0.9927 & 0.0376 & 9228 \\
\hline 16 & -3.023 & 14.399 & -2.1304 & 0.154211 & -0.0054065 & 0.000073436 & 0.9897 & 0.0406 & 12801 \\
\hline 21 & 2.871 & 12.012 & -1.7385 & 0.122437 & -0.0041539 & 0.000054409 & 0.9957 & 0.0290 & 17354 \\
\hline 22 & 2.293 & 11.8415 & -1.6702 & 0.115163 & -0.0038346 & 0.000049352 & 0.9918 & 0.0413 & 47285 \\
\hline 27 & 12.261 & 8.411 & -1.2001 & 0.083220 & -0.0027641 & 0.000035274 & 0.9944 & 0.0361 & 3962 \\
\hline 28 & -22.878 & 20.130 & -2.7366 & 0.182120 & -0.0058882 & 0.000074004 & 0.9942 & 0.0372 & 1959 \\
\hline
\end{tabular}




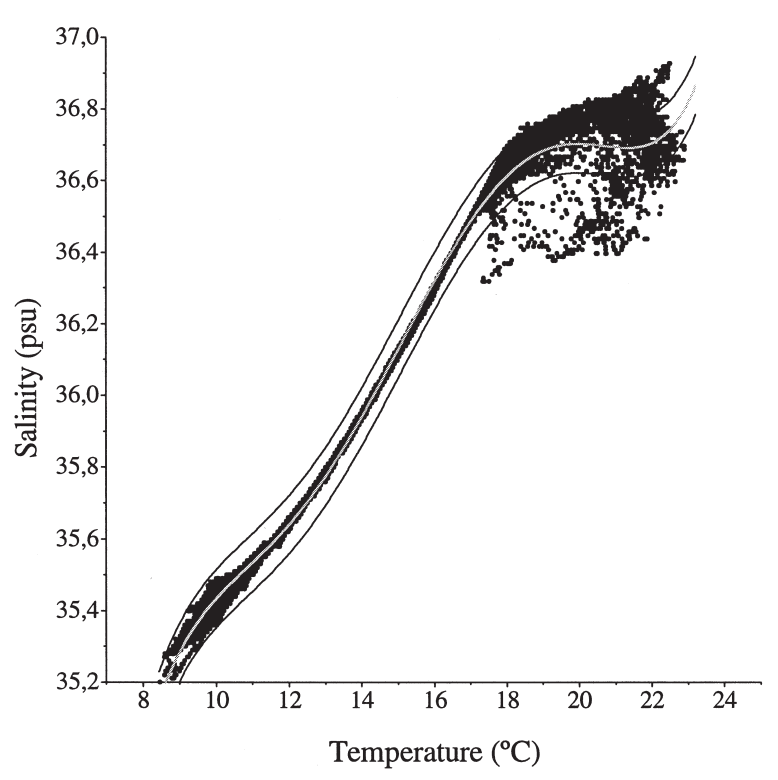

FIG. 2. - Empirical $S(T)$ relationships derived from all available CTD data for zone $22\left(26-28^{\circ} \mathrm{N}, 15-17^{\circ} \mathrm{W}\right)$. The salinity and temperature values correspond to: August and October 1970; January, February and March 1971; January 1972; October 1991; August 1993 and September 1994 (total data: 47398). The polynomial fit (degree 5) is represented by a grey line (statistical properties: Rsquare $=0.9918, \mathrm{SD}=0,0415$ in salinity). The black lines delimit a region with $95 \%$ confidence prediction.

nomial that best fits the data, while the solid lines indicate the $95 \%$ confidence limits of the prediction. For temperatures lower than $11{ }^{\circ} \mathrm{C}$, at about $650 \mathrm{~m}$ depth, we may appreciate the existence of a small distortion, but always within the above confidence limits. Between 11 and $18^{\circ} \mathrm{C}$ the data show very little dispersion, though they were obtained in several years and seasons, and the polynomial provides an excellent T-S relationship. Above $18^{\circ} \mathrm{C}$, however, the dispersion goes beyond the $95 \%$ confidence limits and we may say that the polynomial fit is poor. Temperatures larger than $18^{\circ} \mathrm{C}$ correspond to depths above $120 \mathrm{~m}$; the high variability is to be expected because these depths are affected by the presence of the seasonal mixed layer in the Canary region. Despite the existence of high variability in the top layer, the correlation coefficient is very high, 0.9918 , and the standard deviation is 0.0415 psu.

\section{APPLICATION TO A HYDROGRAPHIC CRUISE SOUTH OF GRAN CANARIA}

In order to examine the goodness of the above analytic algorithms for carrying out dynamic studies from temperature-depth data, as obtained with
XBTs, we decided to perform a dynamic hindcasting in a region where CTD data were available. The idea was to use the temperature-depth data in conjunction with the analytic T-S relations to derive the salinity and dynamic conditions in the area under study, and to compare these results with those that arise when one uses the full CTD data. It is important to note that the data used for this hindcast are totally independent of the historical data on which the algorithms are based.

The data set used is part of a study of the mesoscalar structures that commonly appear south of Gran Canaria and in the coastal transition zone between the Canary Archipelago and the upwelling region off Northwest Africa, which was carried out during June and July 1998. An opportunity ship from the Spanish Navy named El Ferrol was used during the three days immediately prior to the cruise, to produce a coarse XBT grid that allowed the mesoscalar structures in the area to be located. Figure 3 shows the positions of the XBT stations sampled with El Ferrol and several transects that may be used to examine the mesoscalar structures in the area. A hydrographic cruise colled FRENTES 98 was next carried out on board R/V García del Cid. It consisted of XBT and CTD stations plus direct acoustic current measurements and the deployment of Lagrangian drifters, and was aimed at examining the evolution of the mesoscalar structures.

It is important to note that the region under consideration is particularly complex because of its large spatial variability and because of the presence of shallow water structures that occur in the nearsurface high dispersion portion of the T-S diagram. In the next section we will concentrate on examining the possible errors in our methodology when it is applied to such a complex region. For this reason we will not aim to make a thorough dynamic description of the region but rather we will pay particular attention to the applicability of the method to the near-surface region.

The data obtained from the two ships are used to perform two types of studies. The first one is a forecast of salinity and dynamic quantities using the XBT stations together with the T-S analytic relationships obtained for Zone 22, which is the zone that corresponds to these data. The second study is a hindcast of salinity and dynamic quantities using temperature-depth data extracted from the CTD stations and their comparison with the same quantities as obtained from the full temperature, salinity and depth fields available in the CTD stations. 


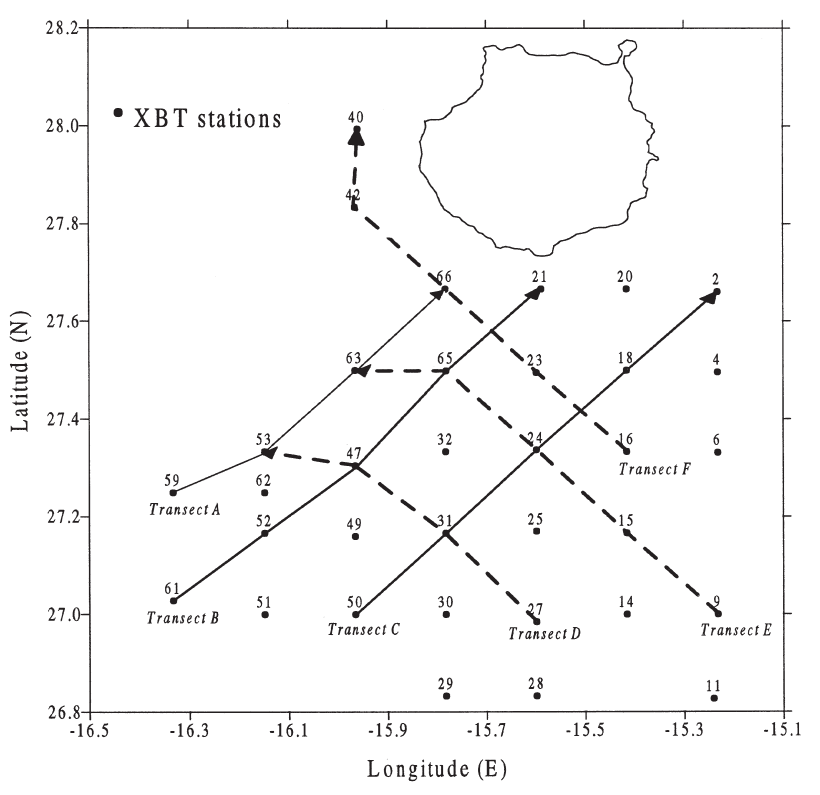

FIG. 3. - Map showing the XBT stations and transects.

\section{RESULTS AND DISCUSSION}

In this section we infer salinity from temperature using the following analytic relationship for Zone 22 (Table 1):

$$
\mathrm{S}(\mathrm{T})=\mathrm{A}+\mathrm{B}_{1} \cdot \mathrm{T}+\mathrm{B}_{2} \cdot \mathrm{T}^{2}+\mathrm{B}_{3} \cdot \mathrm{T}^{3}+\mathrm{B}_{4} \cdot \mathrm{T}^{4}+\mathrm{B}_{5} \cdot \mathrm{T}^{5}
$$

The number of significant digits in each of the coefficients is established from the error analysis results (Sen and Srivastava, 1990; Laws, 1997; Rodríguez-Santana, 1999)

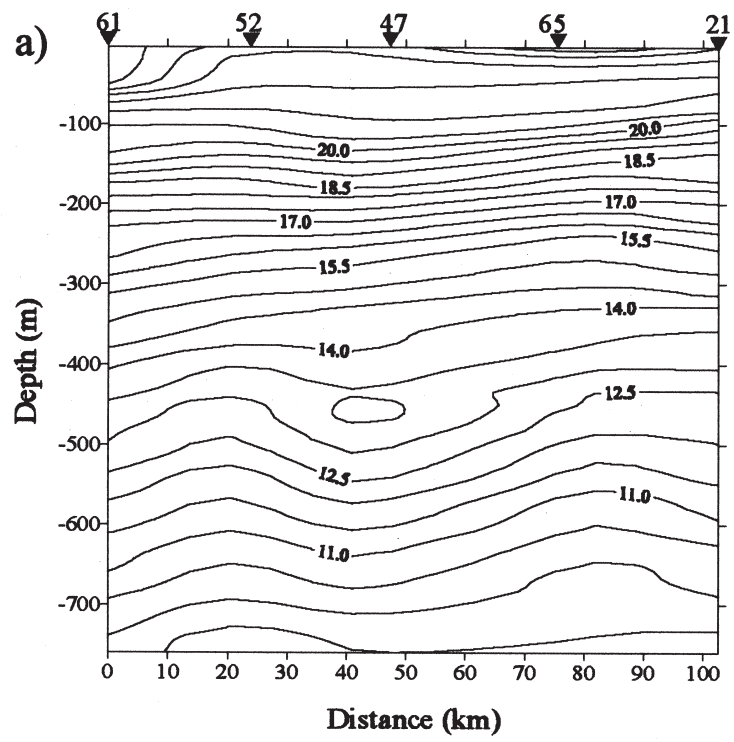

\section{Forecasting of salinity and dynamic quantities from XBT data}

For this study we use the temperature-depth data obtained in 39 XBT stations sampled with the Spanish Navy ship El Ferrol (Fig. 3). The distribution of salinity, potential temperature, potential density, and geostrophic velocity was found along transects A, B, $\mathrm{C}, \mathrm{D}, \mathrm{E}$, and $\mathrm{F}$, also indicated in Figure 3. The arrows indicate the direction followed in each transect, and also our convention for a positive direction used in the calculation of the normal geostrophic velocities.

Figure 4 presents the temperature distribution along Transect $\mathrm{B}$, together with the topography of a near-surface isotherm, $21^{\circ} \mathrm{C}$. The transect illustrates the deepening of the isothermals in what constitutes a large anticyclonic vortex located Southwest of Gran Canaria. Close to the island the vortex is tapped by a very shallow warm water layer, or warm lee filament, which is not present further southwest. The topography of the $21^{\circ} \mathrm{C}$ isotherm clearly illustrates the position of the vortex, with its centre very close to Station 47 located along Transect B.

Figure 5 shows the distribution of potential density along Transect B, as inferred using the temperature-depth data and the T-S analytic relationship. This figure also shows the geostrophic velocity field perpendicular to this transect, with $760 \mathrm{~m}$ as the level of no motion. Positive values correspond to velocities on the page. The velocity field across Section B illustrates the existence of an anticyclonic vortex, its center near its northeastern extreme, at

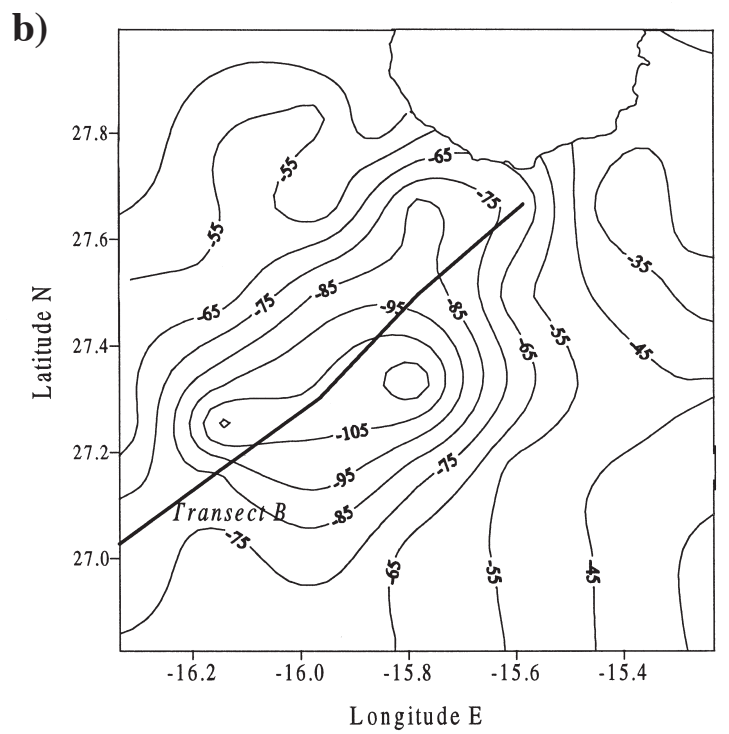

FIG. 4. - (a) Temperature $\left({ }^{\circ} \mathrm{C}\right)$ distribution on Transect B. (b) Topography (m) of the $21^{\circ} \mathrm{C}$ isotherm. 

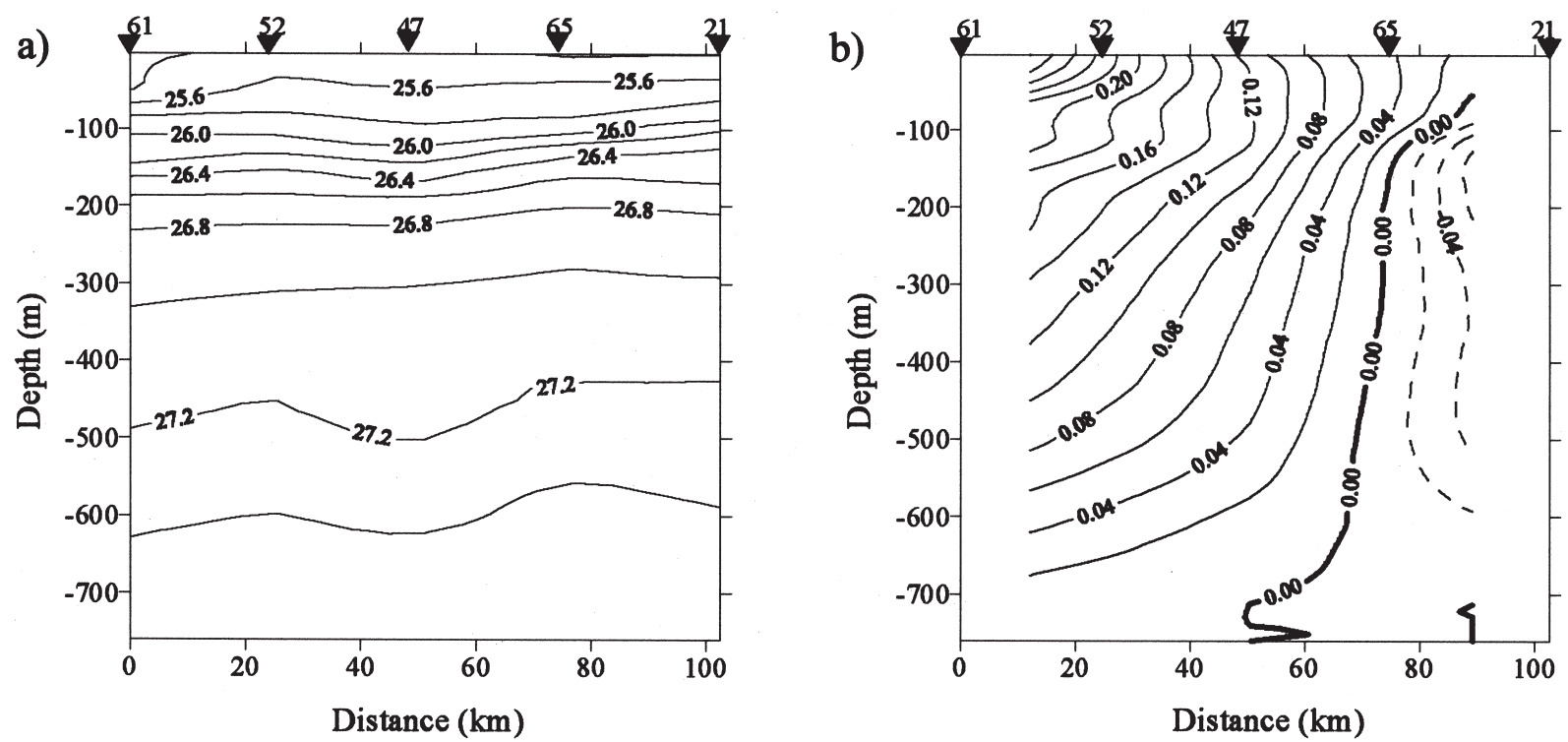

FIG. 5. - (a) Potential density distribution on Transect B derived from XBT data. (b) Geostrophic velocity ( $\left.\mathrm{m} \mathrm{s}^{-1}\right)$ relative to $760 \mathrm{~m}$ on Transect B (positive values are into the paper).

about Station 65, the magnitude of the velocity increasing with distance away from the vortex center. The density and velocity distribution was also calculated along all other transects but, for the sake of brevity, is not show here. The results confirm that the anticyclonic vortex is the dominant structure at the time of the measurements.

We may conclude that the grid of XBT stations provides a gross representation of the main dynamic features in the region. Its main limitation, in the

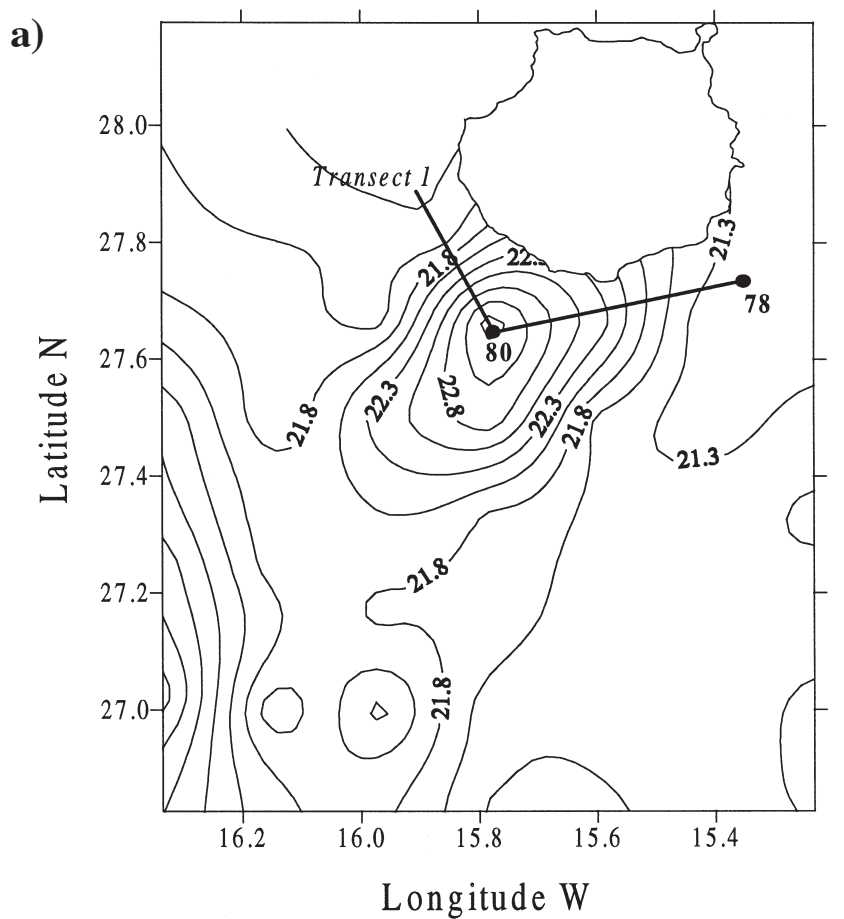

example under consideration, lies in its relatively coarse spatial resolution rather than in the inaccuracies in the estimated salinity fields.

\section{Hindcasting of salinity and dynamic quantities}

Figure 6 shows the temperature distribution at 10 and $100 \mathrm{~m}$ depth using the XBT coarse grid. Over these temperature maps we have drawn the location of Transects 1 and 2, which correspond to CTD sta-

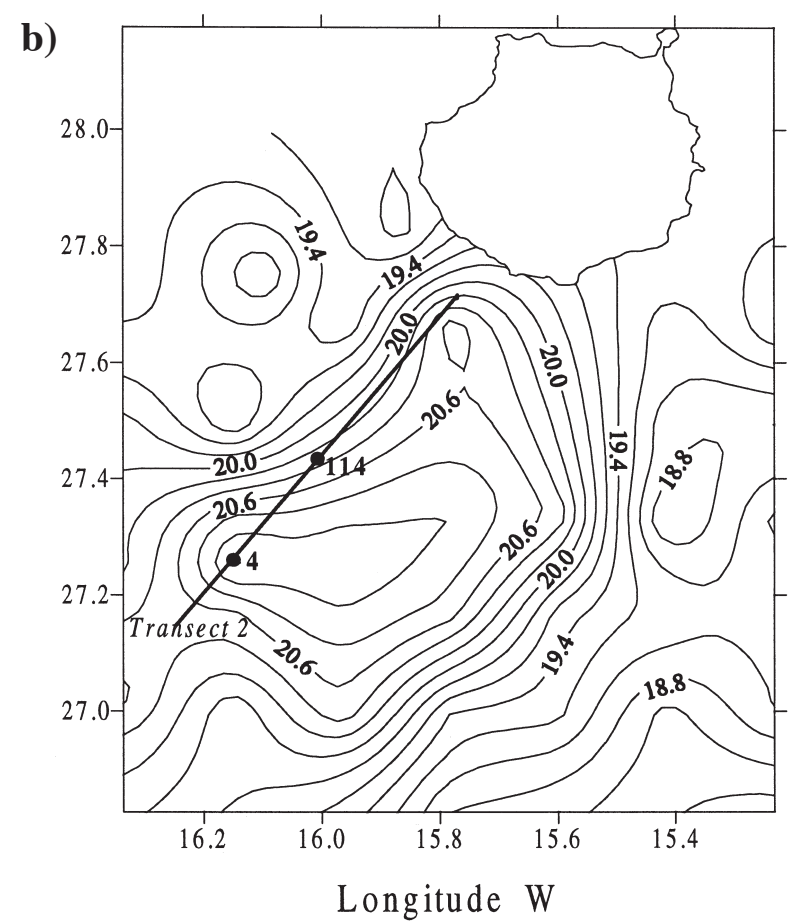

FIG. 6. - Temperature $\left({ }^{\circ} \mathrm{C}\right)$ distribution at depths of (a) $10 \mathrm{~m}$ and (b) $100 \mathrm{~m}$. The location of Transects 1 and 2, as well as the position of Stations $78,80,4$, and 114 , is indicated. 
Salinity (psu)

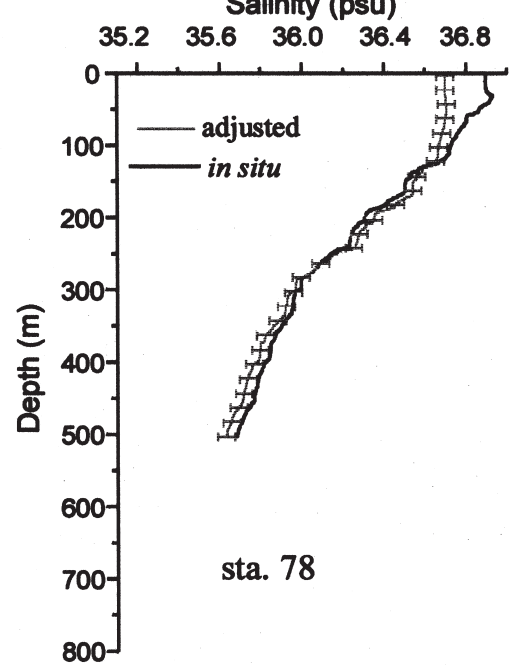

a)
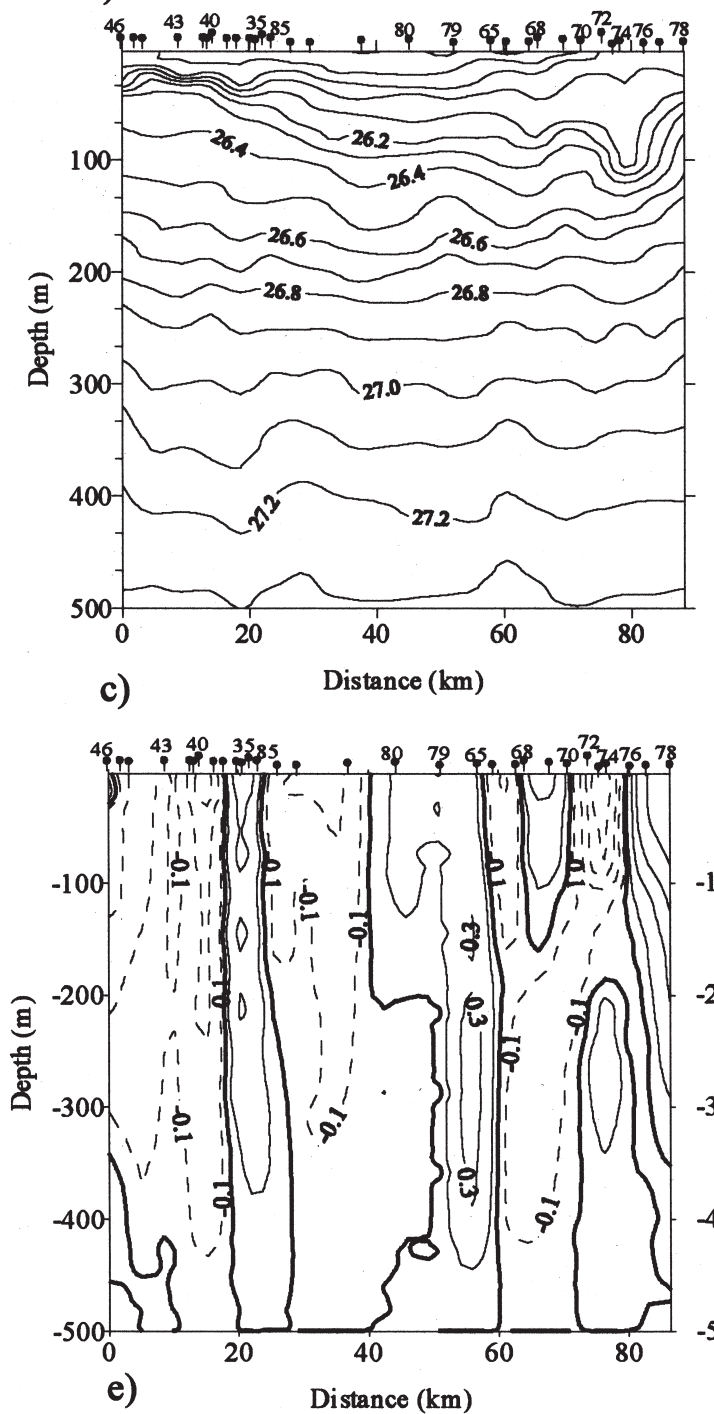

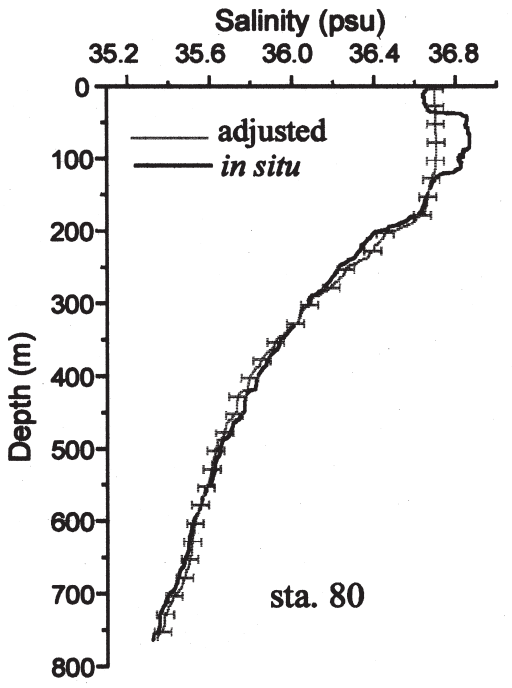

b)

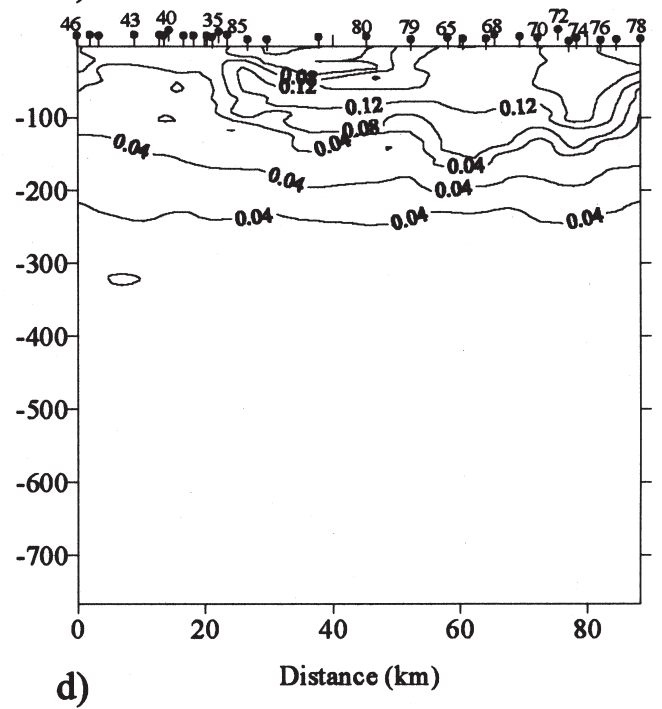

d)

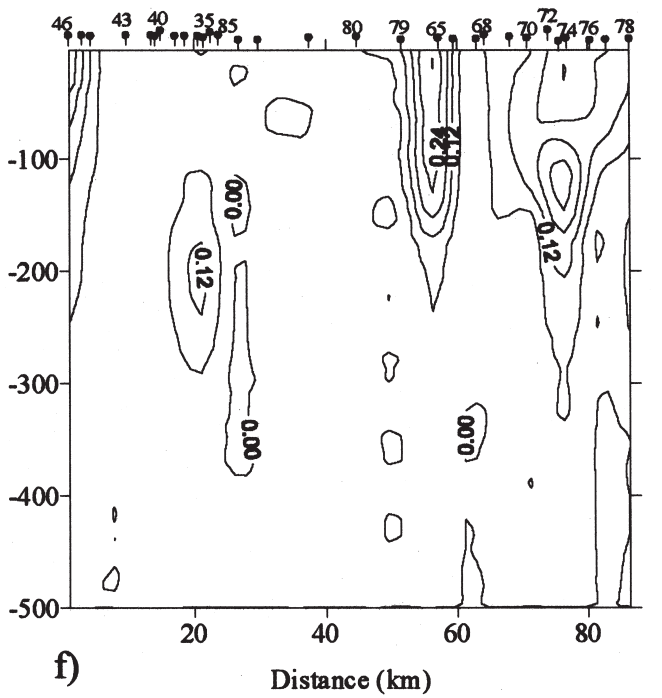

FIG. 7. - Measured and inferred salinity (psu) values at (a) Station 78 and (b) Station 80. (c) Measured potential density and (d) difference between the measured and inferred potential density along Transect 1 . (e) Measured geostrophic velocity $\left(\mathrm{m} \mathrm{s}^{-1}\right)$ and (f) difference between the measured and inferred velocities $\left(\mathrm{m} \mathrm{s}^{-1}\right)$ along Transect 1. 


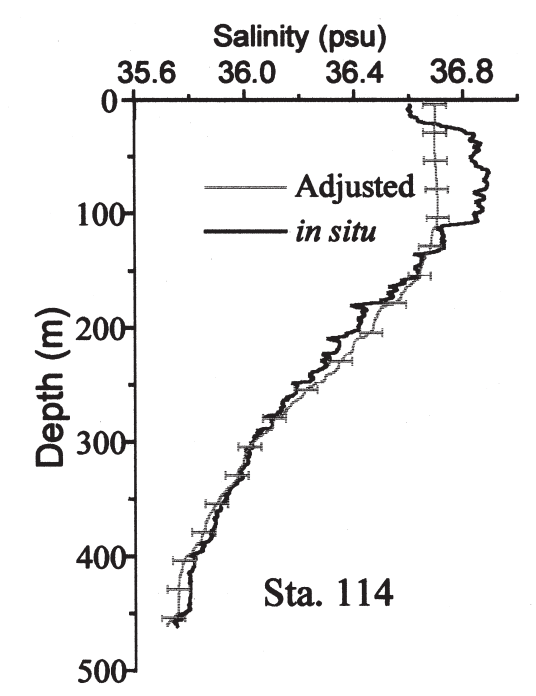

a)
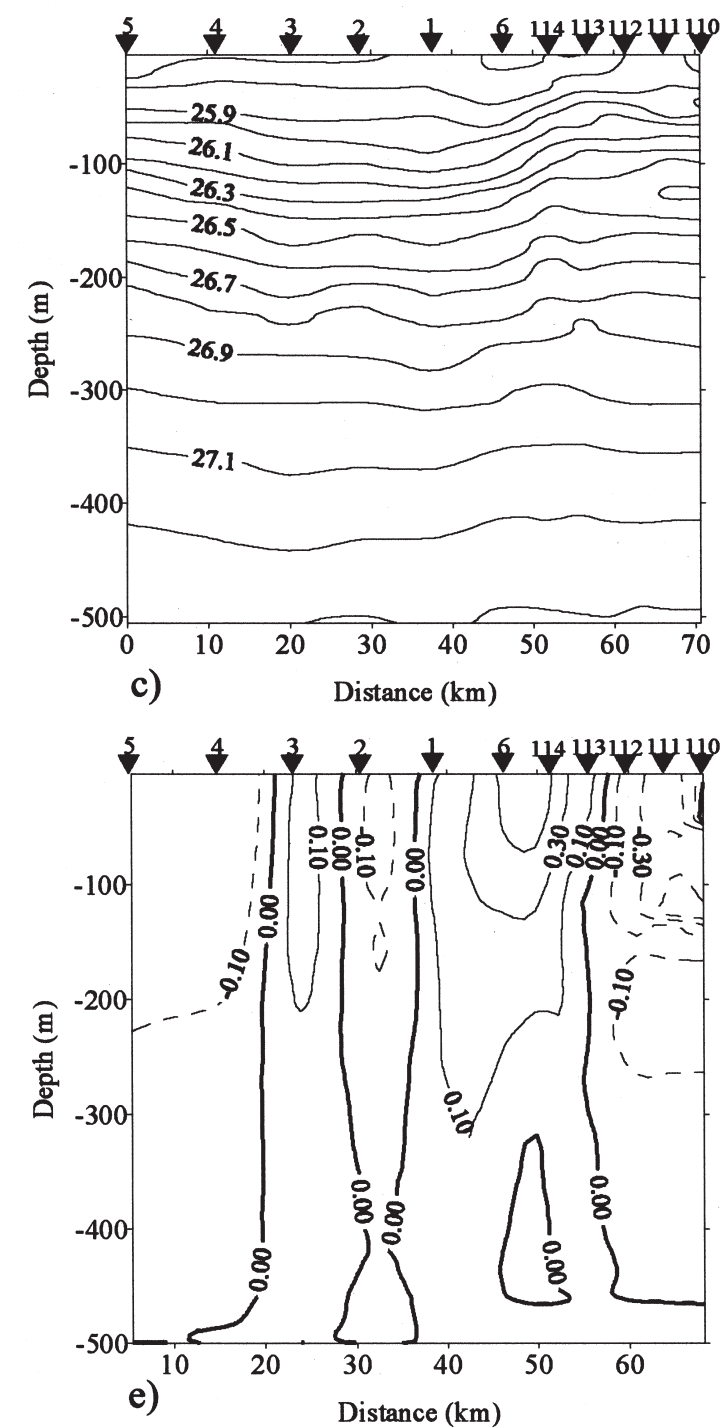

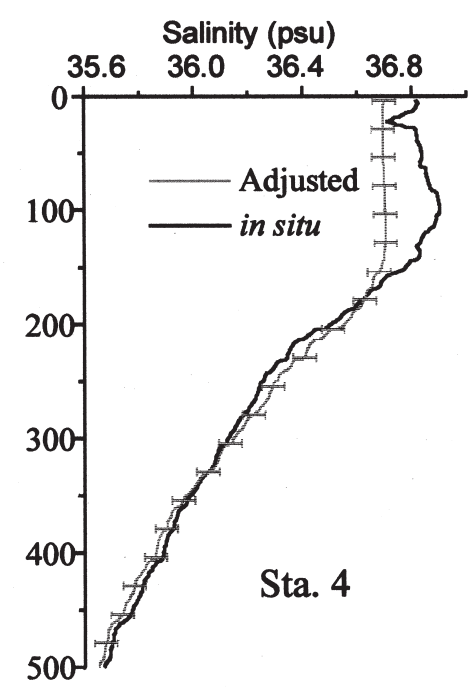

b)
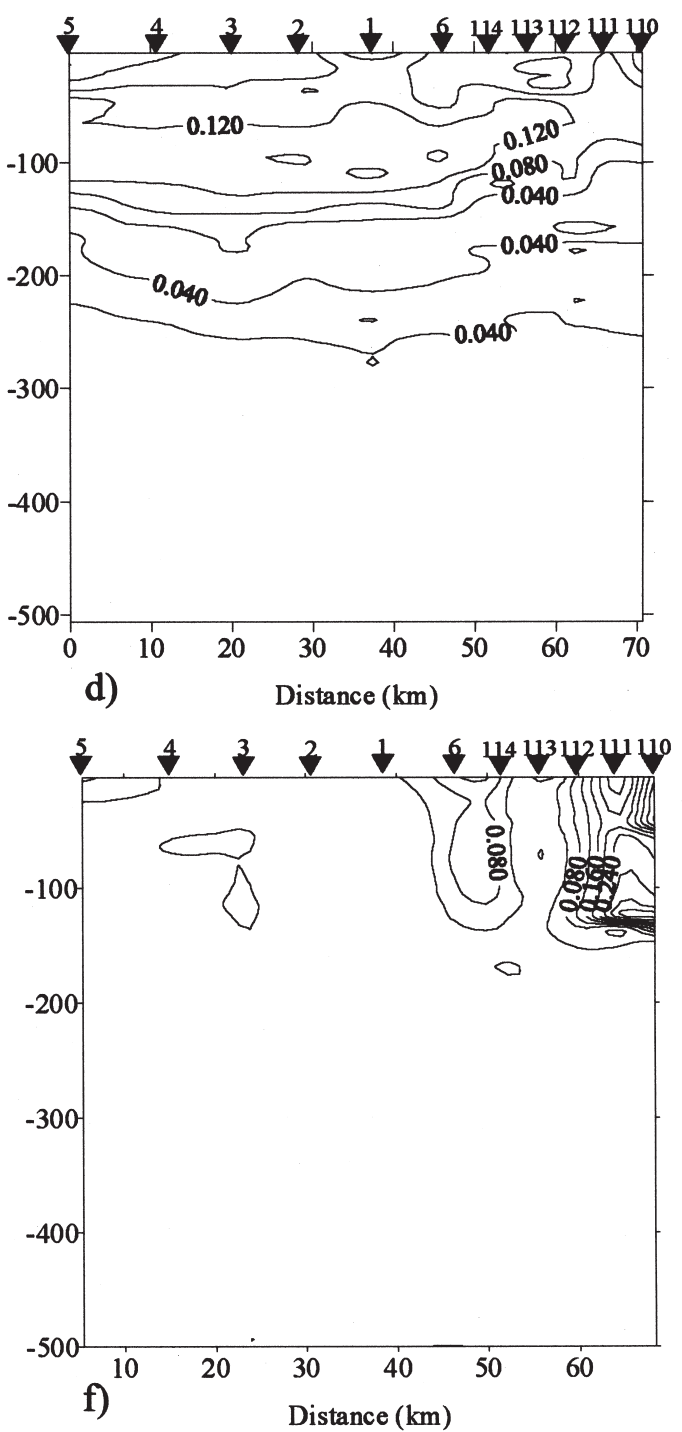

FIG. 8. - Measured and inferred salinity (psu) values at (a) Station 4 and (b) Station 114. (c) Measured potential density and (d) difference between the measured and inferred potential density along Transect 2. (e) Measured geostrophic velocity ( $\mathrm{m} \mathrm{s}^{-1}$ ) and (f) difference between the measured and inferred velocities $\left(\mathrm{m} \mathrm{s}^{-1}\right)$ along Transect 2 . 
tions carried out with the R/V García del Cid. The spatial resolution of these transects is about $5 \mathrm{~km}$, which is much better than the mean resolution of the XBT grid (some $25 \mathrm{~km}$ ). Transect 1 was chosen because it crosses the warm water filament leeward of the island and Transect 2 because it crosses the anticyclonic vortex. In the forthcoming discussion we will refer to "measured" quantities as those either actually measured or calculated using the CTD data, while we will refer to "inferred" quantities as those derived using the temperature-depth field and the analytic T-S relationship.

Figure 7 provides a comparison of the measured and inferred depth-salinity profiles at two stations along Transect 1. It also shows the measured potential density and geostrophic velocity fields (reference level $500 \mathrm{~m}$ ), as well as the difference of these measured fields and the corresponding inferred fields. The inferred salinity profiles at stations 78 and 80 , the latter near the centre of the warm lee filament, show very good agreement with the measured profiles at depths greater than $120 \mathrm{~m}$. In the top $120 \mathrm{~m}$ the inferred salinity values are smaller than the measured ones, probably because our measurements were done in early summer when the surface layer is relatively cool as compared with the mean annual conditions (to which the T-S curve corresponds). This is probably the reason why the agreement is much better in the topmost $50 \mathrm{~m}$ of station 80 , where the warm lee filament water is located. The major differences between the measured and inferred densities and velocities across Transect 1 are again in the top 100-120 $\mathrm{m}$. The maximum deviation in potential density is $0.16 \mathrm{~kg} \mathrm{~m}^{-3}$, a relative deviation of about $0.6 \%$. The corresponding deviation in velocity is as large as $0.28 \mathrm{~m} \mathrm{~s}^{-1}$ in the top 150 $\mathrm{m}$, but always under $0.08 \mathrm{~m} \mathrm{~s}^{-1}$ below $250 \mathrm{~m}$ depths. Figure 8 provides a comparison similar to the one discussed above but for Transect 2, across the anticyclonic vortex. In this case the stations selected are Stations 4, near the vortex centre, and Station 114, at one of the vortex sides. As in Transect 1 the adjustment is reasonably good except in the top 100 (Station 114) or $150 \mathrm{~m}$ (Station 4), this depth being larger near the vortex centre because of its thicker mixed layer. The major differences between measured and inferred values across Transect 2 are in the top 100$150 \mathrm{~m}$. The maximum deviation in potential density is $0.16 \mathrm{~kg} \mathrm{~m}^{-3}$, while the deviation in geostrophic velocity is everywhere relatively small (under 0.08 $\mathrm{ms}^{-1}$ ), except at the northeastern end apparently because of side-effects in the interpolation method.

\section{CONCLUSIONS}

We have used a sample case in the Canary Archipelago region to show that it is possible to obtain a rather good dynamic description from only XBT measurements with the help of T-S analytic relationships. In the case examined, the results turn out to be so good that the reliability of the prediction depends more strongly on the low spatial resolution of the $\mathrm{XBT}$ data than on the intrinsic errors in the proposed methodology.

For quantitative predictions in the Canary basin we have shown that the results are reliable below 100 to $150 \mathrm{~m}$, because this is the depth above which the T-S curve undergoes high dispersion. The presence of mesoscalar structures does not appear to modify the predictions significantly because any distortion affects both the temperature and salinity fields. An exception, however, is where the mesoscalar structures modify the depth of the surface mixed layer, as in anticyclonic vortices where this depth increases. In these regions special caution should be taken when one uses the methodology proposed here.

\section{ACKNOWLEDGEMENTS}

This work was supported by the Spanish government (CYCIT projects AMB95-0731 and MAR961893) and the European Union (MAST project MAS3-CT96-0060). We wish to thank Michaella Knoll for providing the data of cruise P202 and IFREMER for facilitating access to their historical data set.

\section{REFERENCES}

Arístegui, J., P. Sangrà, S. Hernández-León, M. Cantón, A. Hernández-Guerra, and J.L. Kerling. - 1994. Island-Induced Eddies in the Canary Islands. Deep-Sea Res., 41: 1509-1525.

Arístegui, J., A. Tett, A. Hernández-Guerra, G. Basterretxea, M.F. Montero, K. Wild, P. Sangrà, S. Hernández-León, M. Cantón, J.A. García-Braun, M. Pacheco, and E.D. Barton. - 1997. The influence of island-generated eddies on chlorophyll distribution: a case study around Gran Canaria. Deep-Sea Res., 44: 71-96 .

Army, L., and N.A. Bray. - 1982. A Standard Analytic Curve of Potential Temperature versus Salinity for the Western North Atlantic. J. Phys. Oceanogr., 12: 384-387.

Barton, E.D. - 1987. Meanders, eddies and intrusions in the thermohaline front off Northwest Africa. Oceanol. Acta, 10: 267-283.

Emery, W.J. - 1975. Dynamic height from temperature profiles. $J$. Phys. Oceanogr., 5: 369-375.

Emery, W.J., and R.T. Wert. - 1976. Temperature-Salinity curves in the Pacific and their Application to Dynamic Height Computation. J. Phys. Oceanogr., 6: 613-617.

Emery, W.J., W. Lee, W. Zenk, and J. Meincke. - 1986. A low-cost 
digital XBT system and its application to the real-time computations of dynamic height. J. Atmos. Oceanic Tech., 3: 75-83.

Flierl, G.R. - 1978. Correcting expendable bathythermograph (XBT) data for salinity effects to compute dynamic heights in Gulf Stream ring. Deep-Sea Res., 25: 129-134.

Hernández-Guerra, A. - 1990. Estructuras Oceanográficas observadas en las aguas que rodean las Islas Canarias mediante escenas de los sensores AVHRR y CZCS. Tesis Doctoral, Universidad de Las Palmas de Gran Canaria.

Hernández-Guerra, A., J. Arístegui, M. Cantón, and L. Nykjaer. 1993. Phytoplankton pigment patterns in the Canary Islands area as determined using Coastal Zone Colour Scanner data. Int. J. Remote Sensing, 14: 1431-1437.

Laws, E. - 1997. Mathematical Methods for Oceanographers. An Introduction. John Wiley \& Sons, 343 pp.

Marrero-Díaz, A., A. Rodríguez-Santana, and J.L. Pelegrí. - 1997. Diagramas T-S analíticos en la Cuenca de Canarias. Obtención de velocidades geostróficas a partir de medidas con XBTs. Resúmenes de comunicaciones de la XXVI Reunión Bienal de la $R S E F$, Las Palmas de Gran Canaria, pp. 447-448.

Navarro-Pérez, E., H.S. Velez-Muñoz, and K.A. Wild. - 1994. BIO Hespérides cruise report: hydrographic fields. European Coastal Transition Zone Islas Canarias MAST Project Report 0031-16, UCNW, $150 \mathrm{pp}$.

Ratsimandresy, A.W., J.L. Pelegrí, A. Marrero-Díaz, A. Hernán-
dez-Guerra, A. Antoranz and A. Martínez. - 2001. Seasonal variability of the upper warmwatersphere in the Canary Basin. Sci. Mar., 65(Suppl. 1): 251-258.

Rodríguez-Santana, A., J.L. Pelegrí, P. Sangrà, and A. MarreroDíaz. - 1999. Diapycnal mixing in Gulf Stream meanders. $J$. Geophys. Res., 104: 25,891-25,912.

Sangrà, P. - 1995. Perturbación de un flujo geofísico por un obstáculo: Aplicación a la Isla de Gran Canaria. Tesis Doctoral, Universidad de Las Palmas de Gran Canaria.

Sen, A., and M. Srivastava. - 1990. Regresion Analysis. Theory, Methods and Applications. Springer-Verlag, New York, 347 pp.

Siedler, G., and L. Stramma. - 1983. The applicability of the T/S method to geopotential anomaly computations in the Northeast Atlantic. Oceanol. Acta, 6: 167-172.

Stommel, H. - 1947. Note on the use of the T-S correlation for dynamic height anomaly computations. J. Mar. Res., 2: 85-92.

Tejera, A. - 1996. Estudio de estructuras oceanográficas mesoescalares en la Cuenca Canaria mediante los altímetros de los satélites Geosat, ERS-1 y Topex/Poseidon. Tesis Doctoral, Universidad de Las Palmas de Gran Canaria.

Tomczak, M., and J.S. Godfrey. - 1994. Regional Oceanography: An Introduction. Pergamon, $422 \mathrm{pp}$.

Velez-Muñoz, H.S. - 1992. Ignat Pavlyuchenkov cruise report: hydrographic field. European Coastal Transition Zone Islas Canarias MAST Project Report 0031-09, UCNW, 150 pp. 